\title{
In Vitro Inhibition of Adhesion of Escherichia coli Strains by Xylitol
}

\author{
Annelisa Farah da Silva ${ }^{1 *}$, Érika Yoko Suzuki ${ }^{1}$, Aline Siqueira Ferreira ${ }^{1}$, Murilo Gomes \\ Oliveira $^{1}$, Sílvio Silvério da Silva ${ }^{2,3}$ and Nádia Rezende Barbosa Raposo ${ }^{1,4}$ \\ ${ }^{1}$ Faculdade de Farmácia; Universidade Federal de Juiz de Fora; 36036-330; Juiz de Fora - MG - Brasil. \\ ${ }^{2}$ Departamento de Biotecnologia; Escola de Engenharia de Lorena; Universidade de São Paulo; Estrada do \\ Campinho, s/n; C. P.: 116; 12602-810; Lorena - SP - Brasil. ${ }^{3}$ Faculdades Integradas Teresa D'Ávila; Av. Peixoto \\ de Castro, 539; 12606-580; Lorena - SP - Brasil. ${ }^{4}$ Laboratório de Neurociências; Faculdade de Medicina; \\ Universidade de São Paulo; São Paulo - SP - Brasil
}

\begin{abstract}
The present study aimed to evaluate xylitol's antimicrobial and anti-adherence activities on Escherichia coli (ATCC $8739)$ and on another clinical strain enteropathogenic E. coli (EPEC). In vitro minimum inhibitory concentration (MIC) test and adhesion assays were performed using 0.5, 2.5 and 5.0\% xylitol. It was found that xylitol did not have antimicrobial properties on these strains. The scanning electron microscopy (SEM) demonstrated that the slides treated with xylitol had a significant reduction in the number of bacilli and the inhibition of microbial adhesion was probably the xylitol's mechanism of action. Xylitol could be a possible alternative on the control of E. coli infections.
\end{abstract}

Key words: Bacterial adhesion, Escherichia coli, Scanning electron microscopy, Xylitol.

\section{INTRODUCTION}

Xylitol is a five-carbon polyalcohol having the same sweetening power as sucrose and is a Generally Recognized as Safe (GRAS) additive by Food and Drug Administration (FDA). Its microbiological and pharmaceutical properties in the control of some diseases have been explored. Xylitol can be obtained through fermentation of agro-industrial residues which is normally discarded in the environment (Silva et al., 1997; Cunha et al., 2006; Branco et al., 2007; Ferreira, 2007).

Recent studies with animals and humans have shown that xylitol has the potential to be used in the treatment of diabetes, lipids metabolism disorders and renal and parenteral lesions, as well as to prevent the otitis media, caries, lung infections and osteoporosis (Mussatto and Roberto, 2002; Ferreira, 2007). There are some reports on the anti-adherent action of xylitol on many bacteria, preventing their microbial adherence to the tissue to be infected (Sajjan et al., 2004; Ferreira, 2007). Sajjan et al. (2004) found that xylitol $(60-80 \mathrm{mg} / \mathrm{mL})$ inhibited $65 \%$ the growth of Burkholderia cepacia complex (BCC), whose absence was related to the success of lung transplant.

Escherichia coli is a Gram-negative bacillus that belongs to the family Enterobacteriaceae and the

*Author for correspondence: nanafarahs@yahoo.com.br 
enteropathogenic E. coli (EPEC) is a variant of great importance as it causes diarrhea in children. Biopsies of the intestinal cells of patients infected with EPEC showed that the bacterium adhered to the surface of the intestinal epithelium in the form of small colonies and caused typical lesions on the infected cells (Silva and Silva, 2005).

Due to the emergence of pathogens resistance to conventional antibiotics, studies are necessary aiming to prevent and/or treat the diseases caused by these microorganisms (Ofek et al., 2003). Thus, this study aimed to evaluate the antimicrobial activity and anti-adherence property of xylitol on Escherichia coli (ATCC 8739), a colonizing strain of the gastrointestinal tract, and other clinical strain (EPEC) of the same bacteria.

\section{MATERIAL AND METHODS}

\section{Microorganisms}

Two strains of Escherichia coli were used: one of them being a strain of the American Type Culture Collection (ATCC) 8739, and the other a wild strain of clinical origin (Escherichia coli enteropathogenic - EPEC) isolated from the feces of a child with diarrheal disease, by Clinical Analysis Laboratory of the University Hospital of the Federal University of Juiz de Fora - MG, Brazil.

\footnotetext{
Antimicrobial activity

The suspension of each strain was prepared with sterile saline $(\mathrm{NaCl} 9.0 \mathrm{~g} / \mathrm{L})$ to $25 \%$ transmission in the Libra S12 spectrophotometer (Biochrom, Denmark). The positive control consisted of $4 \mathrm{~mL}$ of Tryptone Soy Broth (TSB) inoculated with the suspension $10^{3}-10^{4}$ colony-forming units $/ 4 \mathrm{~mL}$. For the negative control, $4 \mathrm{~mL}$ of sterile TSB was used. In order to prepare the test-tubes, $4 \mathrm{~mL}$ of inoculated TSB and $1 \mathrm{~mL}$ of xylitol (purity $>98 \%$, Fluka BioChemika, Switzerland) in three concentrations $(0.5,2.5$ and $5.0 \%)$ were used.

The tubes were incubated in aerobic environment at $37^{\circ} \mathrm{C}$ for $24 \mathrm{~h}$. The minimum inhibitory concentration (MIC) was determined through the turbidity in the cultivation media (Candan et al., 2003). To compare the MIC of xylitol with a reference antibiotic, chloramphenicol in different concentrations $(0.025$ to $250 \mu \mathrm{g} / \mathrm{mL})$ was used. All procedures were carried out in triplicate.
}

\section{Cellular adherence assays}

For each strain, an aliquot of TSB with bacterium was diluted $1: 10(\mathrm{v} / \mathrm{v})$ with $0.1 \mathrm{M}$ phosphate buffer $(\mathrm{pH}=7.4)$. The volume of inoculum with the optical density $(\lambda=600 \mathrm{~nm})$ of 0.01 was calculated for each strain. In group-testing, the inoculum was added to $50 \mathrm{~mL}$ tubes, which contained $25 \mathrm{~mL}$ of TSB, a glass slide, and xylitol $(0.5,2.5$ and $5.0 \%)$. For negative controls, three conditions were used: 1) degreasing solution and slides, 2) slides and TSB, 3) only TSB. The positive control tubes contained the bacterial suspension, TSB, slides and 1) 5.0\% mannose and 2) $5.0 \%$ glucose. All these were incubated at $37^{\circ} \mathrm{C}$ for $48 \mathrm{~h}$. Afterwards, the slides were removed and placed in the tubes individually. The bacterial suspensions contained in these tubes were inoculated in Tryptone Soy Agar (TSA) and incubated for $24 \mathrm{~h}$ at $37^{\circ} \mathrm{C}$ for subsequent counting of colony-forming units (CFU). The slides were washed (two times) with $10 \mathrm{~mL}$ of $0.1 \mathrm{M}$ phosphate buffer $(\mathrm{pH}=7.4)$, then $10.0 \mathrm{~mL}$ of the same buffer was added to the tubes, which were sonicated (two cycles of $10 \mathrm{~min}$ ) to $40 \pm 6 \mathrm{kHz}$. After sonication, the slides were again washed (two times) with $0.1 \mathrm{M}$ phosphate buffer $(\mathrm{pH}=7.4)$ and fixed with $1 \%$ glutaraldehyde for $12 \mathrm{~h}$. After this, the slides were washed (two times) with 0.1 $M$ phosphate buffer $(\mathrm{pH}=7.4)$, dehydrated with increasing concentrations of ethanol (50 to 100\%) with an interval of 20 minutes between each exchange, and dried at room temperature. Finally, the slides were metallised in Balzers Union FL 9496 metallised (Balzers, Germany) with $2 \mathrm{~nm}$ of gold for two minutes, and subsequently analyzed in the scanning electron microscope JSM 5310 (Jeol, Japan) in high vacuum in secondary electron mode. In parallel, serial dilutions were prepared with each solution after sonication $\left(10^{-2}\right.$ to $\left.10^{-3}\right)$, and they were inoculated on TSA plates and incubated for $24 \mathrm{~h}$ at $37^{\circ} \mathrm{C}$ in order to study the growth of the colonies that had not adhered to the slides (Ferreira et al., 2009). The analyses of the slides before sonication and washing steps were not performed by SEM because at this moment the test specimen remained full of proteins, carbohydrates and other compounds of culture medium (visible to the naked eyes) which compromised the visualization of E. coli colonies by SEM. Therefore, aiming to assess whether xylitol was capable or not to minimize the 
adherence of tested E. coli strains, the comparison between the slides exposed to xylitol and positive control slide (glucose) was considered (Brassart, et al., 1991; Ferreira, 2007) The test with mannose was performed aiming to obtain an exploratory result about the fimbriae of each one of the straintest.

The dilution that offered best conditions of counting was used to achieve the experimental protocols. The counting of CFU, both bacterial suspensions in TSB and the solutions after sonication, was performed in duplicate. The counting results of the colonies that had not adhered to the slides were expressed as mean \pm standard deviation $(\mathrm{n}=2)$. Correlation analysis between the concentration of xylitol and the number of cells detached (average of duplicate) by parametric test of Pearson $(p<0.05)$ was done.

\section{RESULTS}

\section{Antimicrobial activity}

No inhibition of bacterial growth by xylitol at 0.5 , $2.5,5.0 \%$ was observed for $E$. coli strains. For both the strains, turbidity was not observed in the negative control, but there was turbidity in the tubes with xylitol in the three concentrations. This turbidity was comparable to the one in the positive control indicating bacterial growth. The turbidity in the tubes containing chloramphenicol occurred differently. For E. coli strain ATCC 8739, the MIC was $25 \mu \mathrm{g} / \mathrm{mL}$ of chloramphenicol, whereas for EPEC strain, it was $250 \mu \mathrm{g} / \mathrm{mL}$.

\section{Anti-adherence property}

\section{Bacterial growth}

For both the E. coli strains, in all the plates containing TSA and $1 \mathrm{~mL}$ of bacterial suspension of TSB, xylitol did not inhibit the growth, which corroborated the result find on MIC assay.

\section{Bacterial detachment}

The quantitative result of cellular adherence assays was represented by the CFU after sonication count, that is to say, by the number of bacilli not adhered to the test specimen. This result was relevant to assess whether the compound added to xylitol had the property of preventing / mitigating the adherence of tested microorganisms.

The counting of the plates of E. coli strain ATCC 8739 incubated with TSA and $1 \mathrm{~mL}$ of solution after sonication at the dilution $10^{-2}$ is shown in Table 1. In the negative control plates, there were no cells, showing the sterility of the process. In the positive control (glucose), a smaller number of CFU was expected, when compared to the number of cells detached from the plates with xylitol, hence most of the bacilli should be adhered to slides. However, a large number of the cells was found. In the positive control (mannose), the same was observed: a high number of CFU was detached. The relationship between the bacterial detachment and the concentrations of xylitol was positive $(\mathrm{p}<0.01 ; \mathrm{r}=0.969)$.

The counting of the plates of EPEC strain incubated with TSA and $1 \mathrm{~mL}$ of solution after sonication at the dilution $10^{-3}$ is shown in Table 1 . In the negative control plates, there were no cells, showing the sterility of the process. In the positive control (glucose), a high number of cells adhered to the slides and also a considerable number of detached cells were found. In the positive control (mannose), the number of CFU detached was far below the count of the other strain-test. The relationship between the bacterial detachment and the concentrations of xylitol was positive $(p<0.05$; $\mathrm{r}=0.877$ ).

Table 1 - Bacterial detachment of E. coli ATCC 8739 and EPEC strains in experimental treatments

\begin{tabular}{|c|c|c|}
\hline \multirow[b]{2}{*}{ Treatments } & \multicolumn{2}{|c|}{ Bacterial Detachment * } \\
\hline & $\begin{array}{c}\text { Escherichia coli } \\
\text { ATCC 8739 } \\
\left(\text { dilution } 10^{-2}\right)\end{array}$ & $\begin{array}{c}\text { Enteropathogenic } \\
\text { Escherichia coli } \\
\left(\text { dilution } 1^{-3}\right)\end{array}$ \\
\hline Negative control (TSA) & 0 & 0 \\
\hline Positive control (5.0\% glucose) & $>500$ & $286 \pm 11$ \\
\hline Positive control (5.0\% mannose) & $436 \pm 34$ & $16 \pm 3$ \\
\hline $0.5 \%$ Xylitol & $89 \pm 6$ & $198 \pm 28$ \\
\hline $2.5 \%$ Xylitol & $187 \pm 12$ & $282 \pm 20$ \\
\hline $5.0 \%$ Xylitol & $257 \pm 30$ & $311 \pm 30$ \\
\hline
\end{tabular}

* Results expressed as mean \pm standard deviation $(\mathrm{n}=2$ plates $)$. 


\section{Bacterial adhesion}

The observations of microphotographs obtained by SEM and the counting of detached colony-forming units indicated that the mechanism of action of xylitol was based on the prevention of bacterial adhesion. In the experiment with E. coli ATCC 8739 (negative control), cell shaped particles were not found, indicating that the treatment of the slides was appropriate (Figure 1A). There were significant amounts of cells both in the positive control - glucose (Figure 1B) as well as in the positive control - mannose (Figure 1C) indicating that the bacilli were, in fact, adhered on the slides. However, in the samples incubated with $0.5 \%$ xylitol (Figure 1D) and 5.0\% xylitol (Figure 1F), cells were not observed, whereas in the samples incubated with $2.5 \%$ xylitol (Figure 1E), rare bacilli were observed.
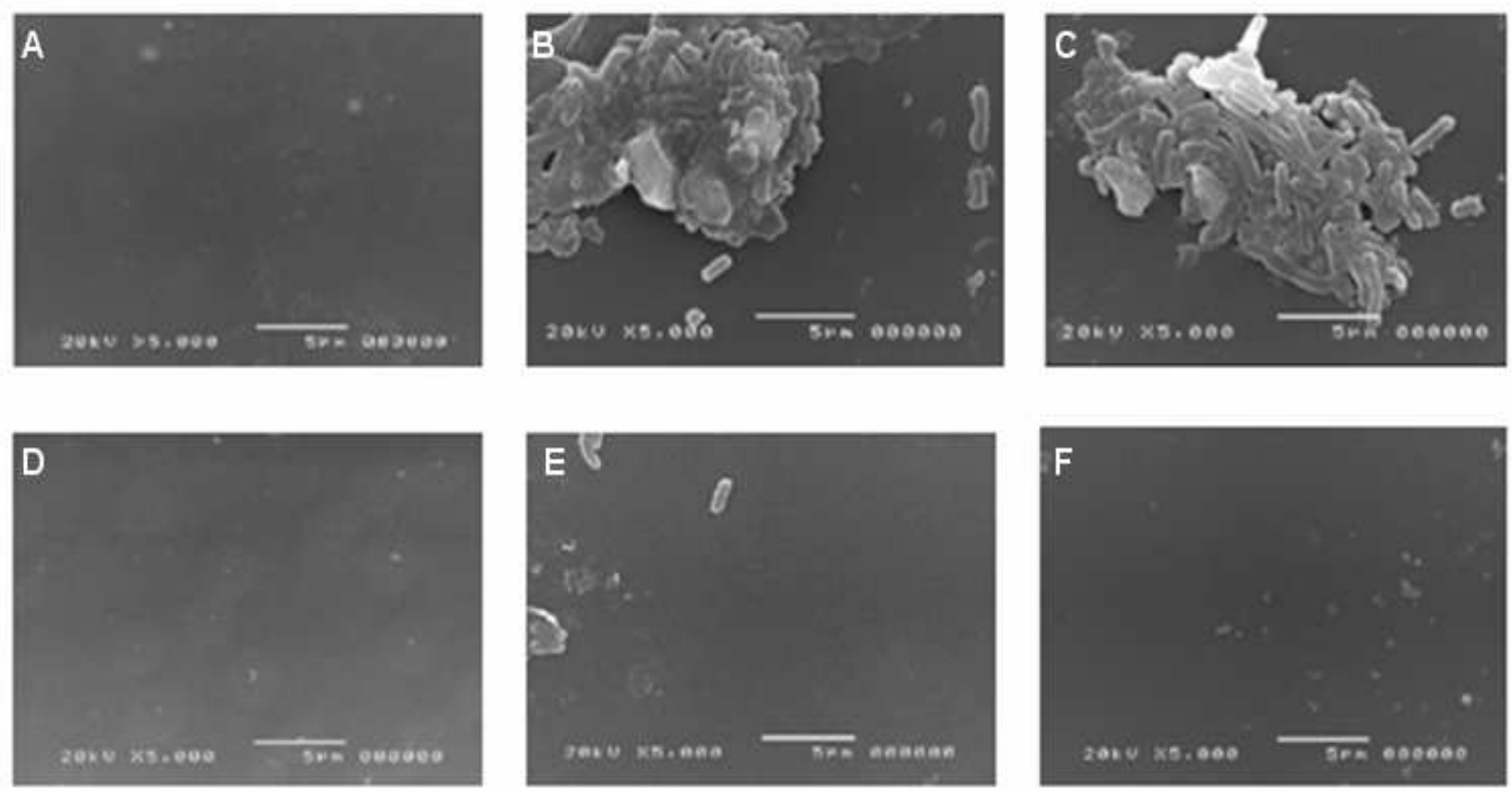

Figure 1 - SEM images showing the effect of xylitol on the adhesion of E. coli ATCC 8739. The strain was treated with $0.5 \%$ xylitol (Panel D), 2.5\% xylitol (Panel E) and 5.0\% xylitol (Panel F). Panel A: negative control, Panel B: treatment with glucose and Panel C: treatment with mannose.

In the experiment with EPEC, cell shaped particles were not found in the negative control (Figure 2A). There were significant amounts of cells only in the positive control - glucose (Figure 2B), indicating that the bacilli were adhered on the slides, while in the positive control - mannose (Figure 2C), there were no cells. On the other hand, in the samples incubated with $0.5 \%$ xylitol (Figure 2D), 2.5\% xylitol (Figure 2E) and 5.0\% xylitol (Figure 2F), there were rare bacilli. In all the three concentrations, there was a significant reduction in the number of adhered cells compared with the positive control (glucose). 

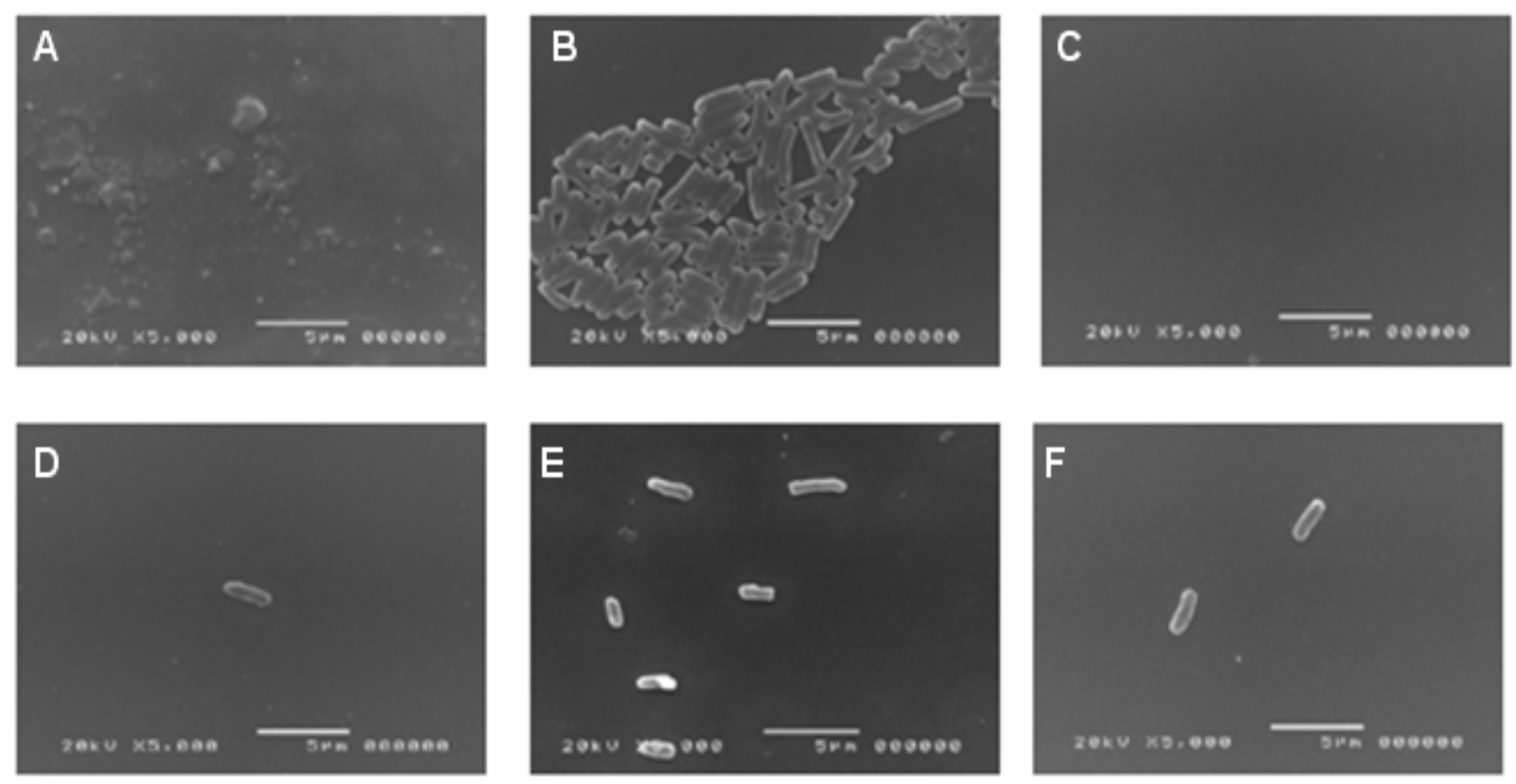

Figure 2 - SEM images showing the effect of xylitol on the adhesion of E. coli EPEC. The strain was treated with $0.5 \%$ xylitol (Panel D), $2.5 \%$ xylitol (Panel E) and 5.0\% xylitol (Panel F). Panel A: negative control, Panel B: treatment with glucose and Panel C: treatment with mannose.

\section{DISCUSSION}

\section{Antimicrobial activity}

The results of antimicrobial activity test showed that xylitol, at the tested concentrations, did not have bactericidal or bacteriostatic action on tested strains. The turbidity in the tubes containing chloramphenicol occurred differently showing that the clinical strain, isolated from the patient hospitalized, had a greater resistance to the chloramphenicol antibiotic than the ATCC strain, confirming its higher pathogenic potential. The indiscriminate use of antimicrobials plays an important role in the selection of resistant strains, and probably, it is the primordial cause of resistance, mainly observed in a hospital environment, where the use of these drugs is more frequent.

\section{Anti-adherence property \\ Bacterial growth}

The result was already expected since xylitol in the three concentrations tested in MIC did not prevent bacterial growth. Thus, these results confirmed that xylitol $(0.5,2.5$ and $5.0 \%)$ had no bactericidal or bacteriostatic action on the two strains tested.

\section{Bacterial detachment}

For the E. coli strain ATCC 8739, the high number of cells detached in the positive control (glucose) and in the positive control (mannose) could be explained by the increase of nutrients availability and bacterial multiplication, resulting in a high number of cells adhered to slides and in a high number of released cells. Furlan and Castro (2001) and Silva et al. (2007) suggested that the presence of glucose in the culture medium improved the specific rates of microbial growth. However, the positive control (mannose) count was lower than the positive control (glucose) count, probably because this was the first sugar to be chosen for the metabolism of bacteria. A considerable number of CFU detached representing the possible antiadherent action of xylitol. For this strain, there was a dose-dependent relation since there was a positive correlation between the bacterial detachment and concentrations of xylitol.

For the EPEC strain, the high number of cells detached in the positive control (glucose) could also be explained by the addition of nutrients in the culture medium with the supply of glucose causing an increased bacterial multiplication. The number of CFU detached, in the positive control (mannose), were far below the count of the other 
strain, due to the analysis of EPEC being based on the dilution $10^{-3}$, whereas E.coli ATCC 8739 was analyzed in dilution $10^{-2}$. For this strain, a considerable number of $\mathrm{CFU}$ detached. The positive correlation between the bacterial detachment and concentrations of xylitol indicated a dose-dependent relation again.

Naaber et al. (1996) also found a dose-dependent inhibition of Clostridium difficile adherence to Caco-2 cells, using 1.0, 5.0 and $10.0 \%$ xylitol. The authors were unaware of the mechanism of action involved, but suggested that it could occur, in vivo, in intestinal cells.

\section{Bacterial adhesion}

For both the E. coli strains, at all the three concentrations of xylitol, there was a significant reduction of microbial adhesion. The results indicated that xylitol's mechanism of action was based on preventing the bacterial adherence. Other studies in the literature also support this antiadherent hypothesis. Söderling and HietalaLenkkeri (2010) found that $4 \%$ xylitol inhibited glass adhesion of six oral streptococci strains, which indicated that xylitol could contribute to decrease the plaque accumulation. These authors also observed that the adherence mechanism was not dependent on the growth inhibition. Ammouns et al. (2009) found the 5\% xylitol could prevent biofilm formation, in vitro, of a wound clinical isolated strain of Pseudomonas aeruginosa. Kontiokari et al. (1998) evaluated the adherence of microorganisms in the presence of 5\% xylitol which prevented the Streptococcus pneumoniae adhesion, and, in a lesser proportion, the Haemophilus influenza adhesion. Tapiainen et al. (2004) observed changes in the capsule and cell wall of Streptococcus pneumoniae after exposure to xylitol (0.5 - 5.0\% in two hours). The cell wall became more diffused and the polysaccharide capsule became rougher. The phenotype of all the strains tested, before exposure to sugar, was opaque and almost became transparent during the experiment. It was suggested that the ability of xylitol to change the structure of bacteria was responsible for inhibiting the adhesion and, therefore, for the changes in microorganisms virulence.

For the EPEC strain, there were no cells in the positive control - mannose (Figure 2C). One possible explanation for this in vitro study could be based on the fact that the EPEC strains had, among other adherence factors, fimbriae type 1 or mannose-sensitive (Brito et al., 2004). Therefore, when mannose was present in the medium, the adherence of bacteria to the slides was obstructed. The bacterial fimbriae recognize some soluble carbohydrates that lead to adhesion blockage, in vitro, of some bacteria (Sharon and Ofek, 2000; Sharon, 2006). The presence of this type of fimbriae is common in the samples of E. coli from urinary and faecal origin (Girón, 1993; Brito et al., 2004).

The effects of some compounds on the adherence of microorganisms are recent and there are few studies in the literature addressing this application (Ofek and Sharon, 2000). The present results indicated the importance of studying the antiadhesive property of xylitol on other gastrointestinal tract microorganisms. The infections of the gastrointestinal tract may involve microorganisms which are multi-resistant to some drugs and, therefore, health professionals should avoid, whenever possible, the administration of antibiotics. The carbohydrates are related to the future of anti-adherent therapy and they may become the first chosen drug in the treatment of many infectious diseases.

Xylitol, at all tested concentrations, had no antimicrobial activity on the tested strains of $E$. coli, but it demonstrated the inhibition of microbial adhesion. The new application of xylitol is an alternative therapeutic option in relation to the conventional antibiotics for the treatment of recurrent infections of the gastrointestinal tract.

\section{ACKNOWLEDGMENTS}

The authors would like to thank CAPES for the scholarship and PIBIC/CNPq and FAPESP for financial support. They would also like to thank Augusto Vieira and Noêmia Rodrigues for technical assistance and Fundação André Tosello for standard E. coli strain donation.

\section{REFERENCES}

Ammons, M.C.B., Ward, L.S., Fisher, S.T., Wolcott, R.D. and James, G.A. (2009), In vitro susceptibility of established biofilms composed of a clinical wound isolated of Pseudomonas aeruginosa treated with lactoferrin and xylitol. Int J Antimicrob Agents 33, 230-236. 
Branco, R.F., Santos, J.C., Murakami, L.Y., Mussatto S.I., Dragone G. and Silva S.S. (2007), Xylitol production in a bubble column bioreactor: Influence of the aeration rate and immobilized system concentration. Process Biochem. 42, 258-262.

Brassart, D., Woltz, A., Golliard, M. and Neeser, J.R. (1991), In vitro inhibition of adhesion of Candida albicans clinical isolates to human buccal epithelial cells by Fuc $\alpha 1 \rightarrow 2$ Gal $\beta$-bearing complex carbohydrates Infect. Immun. 59: 1605-1623.

Brito, B.G., Vidotto, M.C., Berbel, M.M. and Tagliari, K.C. (2004), Fatores de virulência presentes em amostras de Escherichia coli uropatogênicas - UPEC para suínos. Cienc Rural 34, 645-652.

Candan F., Unlu M., Tepe, B., Daferera, D., Polissiou, M., Sökmen, A. and Akpulat, A. (2003), Antioxidant and antimicrobial activity of essential oil and methanol extracts of Achillea millefolium subsp. millefolium Afan. (Asteraceae). J Ethnopharmacol 87, 215-220.

Cunha, M.A.A., Converti, A., Santos, J.C. and Silva, S.S. (2006), Yeast immobilization in LentiKAts ${ }^{\circledR}:$ a new strategy for xylitol bioproduction from sugarcane bagasse. World J Microbiol Biotechnol 22, 65-72.

Ferreira, A.S. (2007), Estudo de propriedades microbiológicas e toxicológicas do xilitol visando a sua aplicação no controle da dermatite atópica. MSc Dissertation, Engineering School of Lorena at University of São Paulo, Lorena, Brazil.

Ferreira, A.S., Barbosa, N.R., Júnior, D.R. and Silva, S.S. (2009), In vitro mechanism of xylitol action against Staphylococcus aureus ATCC 25923. InCurrent Research Topics in Applied Microbiology and Microbial Biotechnology ed. Mendez-Vilas, A. Seville: World Scientific Publishing Co. Pte. Ltd, pp. 505-509.

Furlan, S.A. and Castro, H.F. (2001), Xylitol production by Candida parapsilosis under fed-batch culture. Braz Arch Biol Technol 44, 125-128.

Girón, J.A., Asy, H.O. and Schoolnik, G.K. (1993), Characterization of fimbriae produced by enteropathogenic Escherichia coli. J Bact 175, 73917403.

Kontiokari, T., Uhari, M. and Koskela, M. (1998), Antiadhesive effects of xylitol on otopathogenic bacteria. J Antimicrob Chemother 41, 563-565.
Mussatto, S.I. and Roberto, I.C. (2002), Xilitol: Edulcorante com efeitos benéficos para a saúde humana. Rev Bras Cienc Farm 38, 401-413.

Naaber, P., Letho, E., Salminen, S. and Mikelsaar, M. (1996), Inhibition of adhesion of Clostridium difficile to Caco-2 cells. FEMS Immunol Med Microbiol 14, 205-209.

Ofek, I., Hasty, D. and Sharon, N. (2003), Antiadhesion therapy of bacterial diseases: prospects and problems. FEMS Immunol Med Microbiol 38, 181191.

Sajjan, U., Moreira, J., Liu, M., Humar, A., Chaparro, C., Forstner, J. and Keshayjee, S. (2004), A novel model to study bacterial adherence to the transplanted airway: Inhibition of Bukholderia cepacia adherence to human airway by dextran and xilitol. J Heart Lung Transplant 12, 1382-1391.

Sharon, N. (2006), Carbohydrates as future antiadhesion drugs for infectious diseases. Biochim Biophys Acta 1760, 527-537.

Sharon, N. and Ofek, I. (2000), Safe as mother's milk: Carbohydrates as future anti-adhesion drugs for bacterial diseases. Glycoconj J 17, 659-664.

Silva, D.D.V., Mancilha I.M., Silva, S.S. and Felipe, M.G.A. (2007), Improvement of biotechnological xylitol production by glucose during cultive of Candida guilliermondii in sugarcane bagasse hydrolysate. Braz Arch Biol Technol 50, 207-215.

Silva, S.S., Ribeiro, J.D., Felipe, M.G.A. and Vitolo, M. (1997), Maximizing the xylitol production from sugarcane bagasse hydrolysate by controlling the aeration rate. Appl Biochem Biotechnol 63/65, 557564.

Silva, J.A. and Silva, W.D. (2005), Escherichia coli enteropatogênica (EPEC), ao contrário da Escherichia coli comensal, adere, sinaliza e lesa enterócitos. Rev Patol Trop 34, 175-196.

Söderling, E. and Hietala-Lenkkeri, A. (2010), Xylitol and erythitol decrease adherence of polysaccharideproducing oral streptococci. Curr Microbiol 60, 2529.

Tapiainen, T., Sormunen, R., Kaijalainen, T., Kontiokari, T.O., Ikaheimo, I. and Uhari, M. (2004), Ultrastructure of Streptococcus pneumoniae after exposure to xylitol. J Antimicrob Chemother 54, 225228. 